\title{
Pain catastrophizing, threat, and the informational value of mood: Task persistence during a painful finger pressing task
}

\author{
Petra A. Karsdorp ${ }^{\mathrm{a}, *}$, Saskia Ranson ${ }^{\mathrm{a}}$, Martien G.S. Schrooten ${ }^{\mathrm{a}, \mathrm{b}}$, Johan W.S. Vlaeyen ${ }^{\mathrm{a}, \mathrm{b}}$ \\ ${ }^{a}$ Department of Clinical Psychological Science, Research Group Behavioral Medicine, Maastricht University, Maastricht, The Netherlands \\ ${ }^{\mathrm{b}}$ Department of Psychology, Research Group Health Psychology, University of Leuven, Leuven, Belgium
}

Sponsorships or competing interests that may be relevant to content are disclosed at the end of this article.

\section{A R T I C L E I N F O}

\section{Article history:}

Received 8 August 2011

Received in revised form 17 February 2012

Accepted 24 February 2012

\section{Keywords:}

Affective-motivational models

Experimental pain

Pain catastrophizing

Task persistence

Threat context

\begin{abstract}
A B S T R A C T
Pain catastrophizing has shown to predict avoidance behavior in acute and chronic pain, but the literature is inconsistent. The present study tested the hypothesis that current mood and threat context moderate the relationship between pain catastrophizing and performance duration. Affective-motivational models postulate that negative and positive moods provide information about whether an activity is respectively threatening or safe. Moreover, it has been proposed that stable cognitive schemas about threat influence behavior particularly in threat-relevant contexts. The present study aimed to establish whether pain catastrophizing is related to less or greater performance duration, when participants experience respectively negative or positive moods, particularly in a high threatening pain context. A 2 mood $\times 2$ threat context between-subjects factorial design was applied in 89 healthy participants with pain catastrophizing as covariate and performance duration during a painful finger pressing task as dependent variables. As predicted, higher pain catastrophizing was associated with less performance duration when participants experienced negative moods. The opposite was found when participants experienced positive moods. Moreover, these relationships were most pronounced in a high threatening pain context. This study suggests that the relationship between pain catastrophizing and performance duration during painful activities is moderated by situational factors such as current mood and threat context.
\end{abstract}

(c) 2012 International Association for the Study of Pain. Published by Elsevier B.V. All rights reserved.

\section{Introduction}

A prevailing model that provides an explanation for the development of chronic pain is the fear-avoidance model (FA) [58]. Central to this model is the role of catastrophic (mis)interpretations of pain. Pain catastrophizing involves an exaggerated negative orientation toward pain and its possible consequences [46] and may give rise to pain-related fear and avoidance, and eventually to more pain and disability [58]. There is accumulating evidence in favor of the FA model [57,58]. Moreover, cognitive behavior treatments targeting catastrophic (mis)interpretations have been shown to be successful in chronic pain [12]. However, the effect sizes are relatively small [12]. Additionally, there are studies that failed to demonstrate a catastrophizing-avoidance relationship $[16,32,33,38,43]$. A possible explanation is that the FA model does not take into account the context in which the pain is experienced.

* Corresponding author. Address: Department of Clinical Psychological Science, Maastricht University, P.O. Box 616, 6200 MD Maastricht, The Netherlands. Tel.: +31 43 3881249; fax: +31 433884155.

E-mail address: P.Karsdorp@maastrichtuniversity.nl (P.A. Karsdorp).
It has been argued that contextual factors may moderate the catastrophizing-avoidance relationship [16,43,59].

Affective-motivational models [31,59] postulate that moods signal goal attainment and may influence performance duration. Research has demonstrated that when people pursue hedonic goals, negative moods signal that the task is unpleasant, whereas positive moods signal that the task is pleasant, leading to respectively task disengagement or continuance. When the goal is to perform well, the same moods have opposing effects on performance duration [8-10,26,27,30,31,39,40,44,45,60]. Individuals who catastrophize about pain may primarily adopt hedonic goals aimed at avoiding the threat of pain, rather than performing well. Research outside the pain field has demonstrated that individuals who tend to catastrophize infer danger on the basis of their negative moods $[2,15,61]$. It could be hypothesized that individuals who catastrophize about pain also infer danger on the basis of their negative moods and safety on the basis of their positive moods, leading to respectively reduced or increased performance duration during painful tasks.

Aside from the role of mood, the degree to which the context is threatening also may influence the catastrophizing-avoidance 
relationship [43,59]. It has been demonstrated that stable cognitive schemas about threat influence behavior, particularly in threat-relevant contexts $[4,6,17,29]$. Therefore, we hypothesized that the catastrophizing-avoidance relationship would be most pronounced when the pain stimulus is highly threatening. The proposed theoretical model is illustrated schematically in Fig. 1.

The aim of the present study was to test whether mood and threat context moderate the relationship between pain catastrophizing and performance duration during a painful task. It was predicted that pain catastrophizing would be related to less performance duration when participants experience negative moods, but to greater performance duration when participants experience positive moods. Moreover, it was predicted that this effect would be most pronounced in a high threatening pain context.

\section{Methods}

\subsection{Participants}

Eighty-nine first-year students from Maastricht University (faculties of Health Science, Psychology, or Medicine) participated in the experiment ( 68 women; $M_{\text {age }}[S D]=21.06$ [2.88]). Exclusion criteria were: 1) pain complaints in the upper extremities, neck, or shoulder during the last week (measured with the question: "Did you have any pain complaints in the neck, shoulder, arm, wrist, or hand during the last week?). One participant was excluded because of technical errors, and 2 participants (from the negative mood, low threat condition and the high threat, positive mood condition) were excluded because their task duration (28 and 39 minutes) deviated more than $3 \mathrm{SD}(\mathrm{SD}=5.50)$ from the mean ( $M=4.33$ minutes). The final sample size consisted of 86 participants (65 women; $\mathrm{M}_{\text {age }}[\mathrm{SD}]=21.10$ [2.90]). None of the participants indicated that they were aware of the hypothesis of the experiment. The ethical committee of Maastricht University approved the study.

Participants were randomly assigned to 1 of 2 experimental threat conditions (low threat, high threat). Subsequently participants were rerandomized to another of 2 experimental mood conditions (positive or negative mood). This resulted in 4 experimental groups.

\subsection{Performance duration}

To measure performance duration during a finger pressing task, participants performed a Martians task. This is an adapted version of the Martians task used in previous research [1,34]. Participants

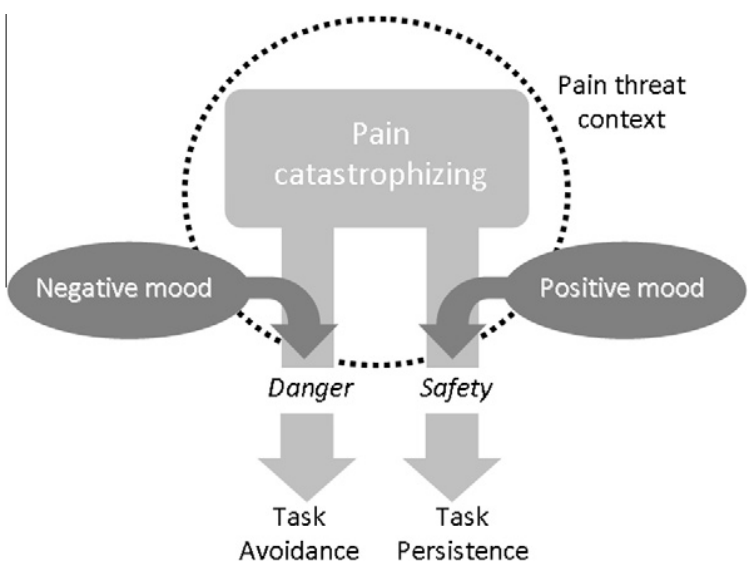

Fig. 1. Schematic representation of an affective motivational model of the relationship between pain catastrophizing and pain behavior. were instructed that the goal of this computer game was to save the planet from a Martians invasion by shooting alien invaders. Invaders appeared on the screen one by one in rows of 10 aliens with a regular speed of 5 invaders per second. Once an alien appeared on the screen, the participant was instructed to shoot the alien by a button press. When the button press was given within $100 \mathrm{~ms}$ after the appearance of the alien, the alien was hit and the picture of the alien was replaced by a picture of an explosion. When the participant missed the alien, its picture remained on the screen. Participants were instructed to press the button and shoot aliens with their index finger of their dominant hand while their wrist was attached to the table with a wristband to avoid extensive movements with their dominant arm. A pilot study $\left[\mathrm{N}=94,22\right.$ male, $\mathrm{M}_{\text {age }}(\mathrm{SD})=21.35$ (2.17)] demonstrated that button pressing in response to circles appearing on the screen one by one with a speed of 5 presses per second for a fixed duration of 5 minutes resulted in painful sensations in the $\operatorname{arm}, F(1,93)=$ 155.98, $P<.001, \eta^{2}=.63$ (with pain ratings of $\mathrm{M}_{\text {before }}[\mathrm{SD}]=1.43$ [1.01] and $\mathrm{M}_{\text {after }}[S D]=3.47$ [1.76] on a 10-point Likert scale). Participants were instructed that there was no right or wrong time to stop the Martians task. They decided for themselves when to end the task by pushing the stop button. Unknown to the participant, the maximal duration of the Martians task was 45 minutes in total. Participants were instructed that at the end of the task they would receive feedback on their total number of hits. Performance duration was registered as the total time spent on the task in minutes. Additionally, to check whether mood, threat context, and pain catastrophizing were associated with physical load and task performance, respectively, the number of space-bar presses per second and proportion of hits and false positives were registered.

\subsection{Threat instruction}

To create a pain-threatening context, 2 threat messages were used. The first message was about the potential risk of getting repetitive strain injury symptoms. To further increase the threat value, the second message was false feedback of muscle electromyography measurement (EMG) in the arm.

The first message was modeled on the threat message developed by Jackson et al. [20] and Boston and Sharpe [3]. In the present study, those in the threat condition received information about the Martians task as "the Repetitive Strain Injury task (RSI task)," whereas the low threat group received information referring to "the Martians task." All information given to the participants was accurate; however, participants in the threat group received information that highlighted some of the physical mechanisms using biomedical terminology and that contained examples of fearinducing physical responses to repetitive movements with the finger (e.g., inflamed tendon sheat). In contrast, the low threat group received information containing common terminology and reassuring examples that the task was harmless (see Appendix A).

The second message was adapted from previous research in which false blood pressure feedback was used to increase the threat value $[52,56]$. In the present study, false arm muscle EMG feedback was used as it was deemed more suitable in a context of a painful finger pressing task (Martians task). Before starting the Martians task, but after the first low or high threat message, participants received a message requesting to sit still for a couple of seconds in order to measure their arm muscle tension. After 10 seconds, those in the threat condition received false feedback of their arm muscle EMG: "According to the electromyography measurement, your muscle tension is rather high but just within the limits to allow participation in the RSI task." The participants in the low threat condition did not receive any message about their muscle tension. 


\subsection{Mood induction}

To induce the appropriate moods, participants were presented with either a positive ("Le Fabuleux Destin d'Amélie Poulain," directed by J. Jeunet, 2001; 4:12 minutes) or negative video excerpt ("Il y'a longtemps que je t'aime," directed by P. Claudel, 2008; 5:05 minutes). Participants were told that the experimenter was interested in the way people evaluate several film fragments [30,31]. Before presentation of the positive or negative excerpt, all participants watched a neutral excerpt. The neutral excerpt was a Belgian weather forecast (4:29 minutes). The excerpt was used to bring the participants in relatively neutral moods at the start of the experiment. Moreover, the excerpt was used to draw participants' attention away from the overall emotional tone of the film clips and thus lessen the chance that the subjects would guess that the film clips were used to influence their moods [31]. After each excerpt, participants completed several questions about the movies to mask the actual purpose of the video excerpts (mood induction) and to give participants the impression that the experiment was about rating movies. The questions were: "Have you seen the fragment of this movie before?", "Can you tell what this movie is about on the basis of this fragment?", "How much attention did you pay to the film fragment?", and "How interesting was the film fragment?"

All 3 excerpts were selected based on a recent study in our laboratory demonstrating that participants $\left(\mathrm{N}=98,22\right.$ male, $\mathrm{M}_{\text {age }}$ $[S D]=22.37$ [5.38]) experienced more negative moods on a 9-point Likert valence scale ranging from 1 (a smiling, happy figure) to 9 (a frowning, unhappy figure) after watching the negative video excerpt $\left[\mathrm{M}_{\text {negative }}(\mathrm{SD})=4.33(1.52)\right]$ than after the neutral excerpt $\left[\mathrm{M}_{\text {neutral }}(\mathrm{SD})=3.38(1.20)\right], F(1,47)=26.59 P<.001, \eta^{2}=.36$. Likewise, participants experienced more positive moods after watching a positive excerpt $\left[\mathrm{M}_{\text {positive }}(\mathrm{SD})=2.72(1.01)\right]$ than after a neutral excerpt, $F(1,52)=41.46, P<.001, \eta^{2}=.44$.

\subsection{Pain catastrophizing}

The Dutch version of the Pain Catastrophizing Scale (PCS) [46,48] was used to assess catastrophic thinking about pain in general. This is a 13-item questionnaire consisting of 3 subscales: helplessness, magnification, and rumination. The PCS total score, which was used in the present research, offers a good index of the catastrophic construct because the 3 subscales are highly correlated. An example of an item is: "I become afraid that the pain will get worse." Ratings are made on a 5-point scale ranging from 0 (not at all) to 4 (always). High mean total scores indicate high levels of pain catastrophizing. Psychometric properties of the Dutch version of the PCS are satisfactory $[7,49,55]$. In the present study, the internal consistency was adequate (Cronbach alpha $=.85$ ).

\subsection{Threat manipulation check}

To test whether the threat manipulation was successful, catastrophic thinking about pain before and after the Martians task was assessed with 2 adapted versions of the 8 -item perceived threat of pain questionnaires (PTP) [56]. One version measured perceived threat before (PTP-A), and the other measured perceived threat during a cold-pressor task retrospectively (PTP-B). For the purpose of the present study, the questionnaires were adapted such that they referred to "the Martians task" as opposed to "the cold pressor task". Examples of the questionnaire before the Martians task were "I wonder whether this test can be harmful for my hand," and "I worry that something serious can happen." For the questionnaire after the Martians task, the items were written in the past tense. Participants were asked to indicate to what extent every statement applied to them on an 11-point scale ranging from 0 (not at all) to 10 (very much). Previous research has shown an adequate internal consistency for both versions [56]. The internal consistency of the present study was also satisfactory for both versions with a Cronbach alpha of .63 and .68 for the PTP-A and PTP-B, respectively.

\subsection{Mood manipulation check}

The Self Assessment Manikin (SAM) [5,23] was used to measure mood valence. The SAM is a nonverbal pictorial assessment technique measuring the 3 major affective dimensions: valence, arousal, and dominance. In the present study, only the valence dimension was used, which consists of one 9-point Likert scale ranging from 1 (a smiling, happy figure) to 9 (a frowning, unhappy figure). Participants were instructed to rate how they felt. The SAM has been used effectively to measure affective reactions to a wide variety of stimuli such as pictures, images, sounds, advertisements, and painful stimuli [5]. In addition to the SAM valence scale, current levels of sadness, anxiety, and happiness were rated on a 5 -point scale. The possible range of scores varied between 1 (not at all) and 5 (very much) [27].

\subsection{Pain intensity and pain unpleasantness}

Experienced pain and pain unpleasantness in the dominant arm was measured before and after the Martians task. Ratings were made on an 11-point Likert scale ranging from 0 (no pain at all) to 10 (the most intense pain imaginable) for pain intensity, and from 0 (not unpleasant at all) to 10 (the most unpleasant pain imaginable) for pain unpleasantness [14,37].

\subsection{Procedure}

Participants were told that the experiment consisted of 2 separate experiments. One experiment was about evaluating situations with minimal information, and the other was about validating a computer task, the so-called Martians task. After signing informed consent, participants completed the PCS and some biographical questions on the internet at home using the electronic environment EMIUM [21]. Next, they were invited to the laboratory and seated in front of a computer. The experimenter attached 3 EMG electrodes to the dominant arm and told participants that muscle tension would be recorded during the second experiment. Subsequently, participants were told that the first experiment was about rating movies. Participants watched a neutral film followed by the film, the mood and pain questions. Next, participants watched 1 of 2 mood films dependent on the mood condition, followed by the film and mood questions. During the so-called second experiment participants received information about the Martians task, including the first low or high threat message about the potential risk of RSI symptoms. Next, an EMG recording took place and false feedback of muscle tension was provided to the participant dependent on the threat condition. Subsequently, participants completed the PTP-A, the pain questions, and the Martians task. After the Martians task, participants completed the pain questions, the mood questions, and the PTP-B. All participants were debriefed about the design and purpose of the study and the false feedback of the EMG recordings immediately after the experiment. Participants received course credits for their participation or $€ 7.50$.

\subsection{Statistics}

To check whether the mood manipulation was successful, a 2 threat (low vs high threat) $\times 2 \operatorname{mood}($ positive vs negative) $\times 3$ time (before mood film, after mood film, vs after Martians task) multivariate analysis of covariance (MANCOVA) was conducted with 
pain catastrophizing as (centered) covariate and the SAM valence scale, happiness, sadness, and anxiety as dependent variables.

Next, to establish whether the threat manipulation was successful, two 2 threat (low vs high threat) $\times 2 \operatorname{mood}$ (positive vs negative) analyses of covariance (ANCOVAs) were performed with pain catastrophizing as (centered) covariate and either the PTP-A or the PTP-B as the dependent variable.

To establish whether the task was painful, two 2 threat (low vs high threat) $\times 2 \operatorname{mood}$ (positive vs negative) $\times 2$ time (before vs after the Martians task) MANCOVAs were performed with pain catastrophizing as (centered) covariate and with either pain intensity or unpleasantness as the dependent variable.

Next, a series of 2 threat (low vs high threat) $\times 2 \operatorname{mood}$ (positive vs negative) ANCOVAs were performed with pain catastrophizing as (centered) covariate. Firstly, we sought to establish whether overall physical load (operationalized by the number of button presses per second) and task performance (proportion of hits or false positives) differed among the 4 experimental conditions and were related to pain catastrophizing. Secondly, we sought to establish whether the relationship between pain catastrophizing and performance duration on the Martians task was moderated by mood and threat context.

Note, that the analysis of performance duration, number of button presses per second, and proportion of hits and false positives were also conducted with the centered variable pain intensity at baseline as covariate. These results were not reported here because they yielded the same significant findings as the analyses without pain intensity as a covariate. Moreover, pain intensity at baseline was not significantly related to number of presses per minute, hits, false positives, and performance duration (all $F s<1.00$ and all Ps > .05).

For all analyses, pain catastrophizing was initially included as a continuous variable and not as a dichotomized between-subjects factor because dichotomization leads to reduced statistical power and less accurate statistical tests $[11,25]$. In case of a significant interaction between pain catastrophizing and the betweensubjects or within-subjects factors, follow-up analyses were performed. Firstly, the effect of pain catastrophizing was tested at each level of the within-subjects or between-subjects factor by means of an ANCOVA and by calculating a Pearson productmoment correlation between pain catastrophizing and the dependent variable. Secondly, subgroups were created scoring high or low on pain catastrophizing based on the median split of the PCS $(\mathrm{Me}=13)$. Subsequently, the $(\mathrm{M})$ ANCOVAs were repeated for the 2 subgroups separately.

\section{Results}

\subsection{Manipulation check}

\subsubsection{Mood manipulation}

Table 1 displays mean mood scores and standard deviations for each mood condition. A 2 threat $\times 2 \operatorname{mood} \times 3$ time MANCOVA with the PCS as covariate demonstrated a main effect of time, $F$ $(8,74)=2.92, P=.01, \eta^{2}=.24$, which was superseded by the expected interaction time $\times \operatorname{mood}, F(8,74)=7.15, P<.001$, $\eta^{2}=.44$. As expected, post hoc tests (note that the results of these post hoc analyses are available on request from the corresponding author) analyzing the time $\times$ mood interaction demonstrated that participants in the positive mood condition experienced more positive moods after the mood film than at baseline (SAM valence, $F$ $[1,37]=28.12, P<.001, \eta^{2}=.43$; happiness, $F[1,37]=13.95$, $\left.P<.001, \eta^{2}=.27\right)$. Participants in the negative mood condition experienced greater negative moods after the mood film than at baseline (SAM valence, $F[1,42]=13.80, P<.001, \eta^{2}=.25$; sadness, $\left.F[1,42]=17.67, P<.001, \eta^{2}=.30\right)$. Overall no significant mood differences emerged between baseline and the end of the Martians task (all $P>.05$ ).

Finally, an overall main effect of pain catastrophizing was demonstrated, $F(4,78)=3.25, P=.02, \eta^{2}=.14$, indicating that higher pain catastrophizing was associated with higher negative moods (SAM valence, $F[1,81]=6.15, P=.02, \eta^{2}=.07, r[86]=.21$; sadness, $\left.F[1,81]=11.51, P=.001, \eta^{2}=.12, r[86]=.30\right)$. There were no other significant main or interaction effects of pain catastrophizing, mood, threat, and time (all $P>.05$ ). These findings suggest that the mood manipulation was successful and was not significantly influenced by threat condition and pain catastrophizing.

\subsubsection{Threat manipulation}

In Table 1, mean threat scores and standard deviations are presented for each threat condition. As expected, a 2 threat $\times 2$ mood ANCOVA with the PCS as covariate demonstrated that experienced threat directly after the threat manipulation was higher in the high than in the low threat condition, $F(1,81)=6.16, P=.02, \eta^{2}=.07$. Moreover, overall higher pain catastrophizing was associated with higher perceived threat directly after the threat manipulation and the Martians task (respectively $F[1,81]=7.49, P<.01, \eta^{2}=.09$, $r[86]=.27$, and $\left.F[1,81]=7.96, P<.01, \eta^{2}=.09, r[86]=.29\right)$. No other main or interaction effects were demonstrated of threat, mood, and pain catastrophizing (all $P>.05$ ). This indicated that the threat manipulation was successful and was not significantly influenced by mood condition and pain catastrophizing.

\subsubsection{Task manipulation}

As expected, a 2 threat $\times 2 \operatorname{mood} \times 2$ time MANCOVA with the PCS as covariate demonstrated a significant main effect of time, $F$ $(1,81)=95.45, P<.001, \eta^{2}=.54$, indicating that participants experienced more pain after the Martians task than before the task (Fig. 2). Moreover, a significant interaction was obtained between the PCS and time, $F(1,81)=5.42, P=.02, \eta^{2}=.06$. Follow-up analyses of this interaction demonstrated that higher pain catastrophizing was associated with higher pain levels after the Martians task, but not before the Martians task (respectively $F$ $[1,81]=5.64, P=.02, \eta^{2}=.07, r[86]=.25$, and $F[1,81]=0.21$, $\left.P=.65, \eta^{2}<.01, r[86]<.01\right)$.

The analysis of pain unpleasantness demonstrated, as expected, a main effect of time, $F(1,81)=92.61, P<.001, \eta^{2}=.53$, indicating that pain was rated as more unpleasant after the Martians task than before. Moreover, the analysis demonstrated that higher pain catastrophizing was associated overall with higher pain unpleasantness ratings, $F(1,81)=4.92, P=.03, \eta^{2}=.06, r$ $(86)=.17$. Finally, a significant interaction effect of time $\times$ mood, $F(1,81)=4.01, P<.05, \eta^{2}=.05$, was found. However, follow-up tests assessing the effect of mood before and after the Martians task separately did not yield significant mood effects (all $P>.05)$. No other significant main or interaction effects were obtained for time, mood, threat, and pain catastrophizing on pain intensity and unpleasantness (all $P>.05$ ). These findings indicate that pain intensity and unpleasantness increased during the task, and that the increase in intensity was stronger for those scoring high on pain catastrophizing. The increase in pain was not significantly influenced by mood and threat condition.

\subsection{Physical load and task performance}

Means and standard deviations of number of responses per seconds, hits, and false positives are presented in Table 2 . As expected, a 2 threat $\times 2$ mood ANCOVA with the PCS as covariate did not yield a significant effect of mood, threat, and pain catastrophizing on number of responses per second (all $P>.05$ ). This indicated that physical load did not differ between the mood and threat conditions and was unrelated to pain catastrophizing. 
Table 1

Means and standard deviation of experienced mood and threat for each mood and threat condition separately.

\begin{tabular}{|c|c|c|c|c|}
\hline & \multicolumn{2}{|l|}{ High threat condition } & \multicolumn{2}{|l|}{ Low threat condition } \\
\hline & $\begin{array}{l}\text { Positive mood condition } \\
\mathrm{M}(\mathrm{SD})\end{array}$ & $\begin{array}{l}\text { Negative mood condition } \\
\mathrm{M}(\mathrm{SD})\end{array}$ & $\begin{array}{l}\text { Positive mood condition } \\
\mathrm{M}(\mathrm{SD})\end{array}$ & $\begin{array}{l}\text { Negative mood condition } \\
\mathrm{M}(\mathrm{SD})\end{array}$ \\
\hline \multicolumn{5}{|l|}{ Valence scale ${ }^{*}$} \\
\hline Baseline & $3.50(1.10)$ & $3.33(1.20)$ & $3.64(1.36)$ & $3.23(1.04)$ \\
\hline After mood induction & $2.67(0.77)$ & $3.79(1.32)$ & $2.95(1.32)$ & $3.86(1.11)$ \\
\hline After task & $3.89(1.28)$ & $3.75(1.42)$ & $3.64(1.14)$ & $3.19(1.03)$ \\
\hline \multicolumn{5}{|l|}{ Happiness } \\
\hline Baseline & $4.00(0.59)$ & $4.29(0.69)$ & $4.00(0.69)$ & $4.00(0.59)$ \\
\hline After mood induction & $4.56(0.62)$ & $4.13(0.74)$ & $4.18(0.80)$ & $4.00(0.84)$ \\
\hline After task & $3.72(0.89)$ & $4.17(0.64)$ & $3.95(0.95)$ & $4.24(0.62)$ \\
\hline \multicolumn{5}{|l|}{ Sadness } \\
\hline Baseline & $2.33(0.69)$ & $2.42(0.72)$ & $2.91(1.01)$ & $2.48(0.87)$ \\
\hline After mood induction & $2.22(0.55)$ & $2.88(0.90)$ & $2.55(0.80)$ & $2.81(0.98)$ \\
\hline After task & $2.50(0.79)$ & $2.54(0.88)$ & $2.50(0.80)$ & $2.48(0.81)$ \\
\hline \multicolumn{5}{|l|}{ Anxiety } \\
\hline Baseline & $2.06(0.24)$ & $2.04(0.20)$ & $2.14(0.47)$ & $1.86(0.36)$ \\
\hline After mood induction & $2.11(0.76)$ & $2.08(0.65)$ & $2.18(0.73)$ & $1.90(0.30)$ \\
\hline After task & $2.06(0.24)$ & $1.96(0.20)$ & $2.00(0.44)$ & $1.90(0.30)$ \\
\hline \multicolumn{5}{|l|}{ Threat } \\
\hline After threat induction, but before task (PTP-A) & $3.01(1.00)$ & $2.99(1.04)$ & $2.76(1.10)$ & $2.32(0.98)$ \\
\hline After task (PTP-B) & $3.56(1.60)$ & $3.61(1.36)$ & $3.42(1.40)$ & $3.34(1.31)$ \\
\hline
\end{tabular}

$\mathrm{M}=$ mean; PTP = perceived threat of pain questionnaire; $\mathrm{SD}=$ standard deviation.

* Low scores indicate positive moods; high scores indicate negative moods.

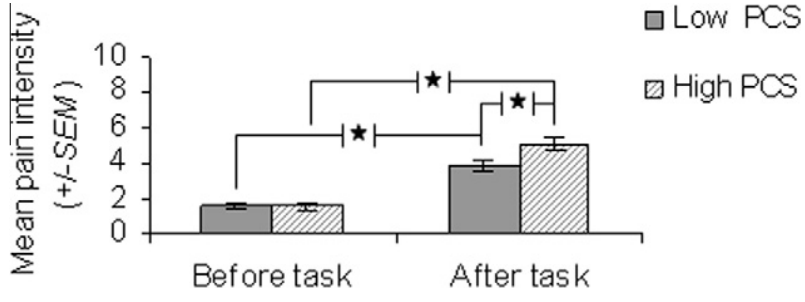

Fig. 2. Mean pain intensity for individuals with high and low pain catastrophizing before and after the Martians task.

When the total number of button presses was divided into hits (button presses when an alien was presented on the screen) and false positives (button presses without the presence of an alien), a marginally significant larger proportion of hits was found among participants with positive than negative moods, $F(1,78)=3.96$, $P=.05, \eta^{2}=.05$. No other main or interaction effects were obtained for mood, threat, and pain catastrophizing on proportion of hits and false positives (all $P>.05$ ).

\subsection{Performance duration}

Means and standard deviations of performance duration are presented in Table 2 . As expected, a 2 threat $\times 2 \operatorname{mood}$ ANCOVA with the PCS as covariate demonstrated a significant 3-way interaction between threat, mood, and pain catastrophizing, $F$ (1, 78 ) $=7.81, P=.007, \eta^{2}=.09$ (Fig. 3). This 3-way interaction consisted of a significant 2-way interaction between mood and pain catastrophizing in the high threat condition, $F(1,38)=9.17$, $P=.004, \eta^{2}=.19$, but not in the low threat condition, $F(1$, $40)=0.33, P=.57, \eta^{2}=.01$. Follow-up tests of the 2 -way interaction in the high threat condition demonstrated that, as expected, high pain catastrophizing was related to greater performance duration in the positive mood condition, $F(1,16)=5.12, P=.04$, $\eta^{2}=.24, r(18)=.49$, but to less performance duration in the negative mood condition, $F(1,22)=6.31, P=.02, \eta^{2}=.22, r(24)=-.47$. Additionally, unexpectedly, participants with low pain catastrophizing (based on median split) showed greater performance duration when in a positive than a negative mood, $F(1,23)=11.51$, $P=.003, \eta^{2}=.33$. No such mood effect was demonstrated for the participants with high pain catastrophizing, $F(1,15)=0.40$, $P=.54, \eta^{2}=.03$. No other main or interaction effects were obtained for mood, threat, and pain catastrophizing (all $P>.05$ ).

\section{Discussion}

The findings of the present study support the conjecture that the relationship between pain catastrophizing and performance duration during painful tasks is moderated by situational factors, such as current mood and threat context. In line with the predictions, the results on performance duration demonstrated that

Table 2

Means and standard deviations of performance duration and task performance for the high and low pain catastrophizers in each mood and threat condition separately.

\begin{tabular}{|c|c|c|c|c|c|c|c|c|}
\hline & \multicolumn{4}{|c|}{ High threat condition } & \multicolumn{4}{|c|}{ Low threat condition } \\
\hline & \multicolumn{2}{|c|}{ Positive mood } & \multicolumn{2}{|c|}{ Negative mood } & \multicolumn{2}{|c|}{ Positive mood } & \multicolumn{2}{|c|}{ Negative mood } \\
\hline & $\begin{array}{l}\text { Low PCS } \\
\mathrm{M}(\mathrm{SD})\end{array}$ & $\begin{array}{l}\text { High PCS } \\
\mathrm{M}(\mathrm{SD})\end{array}$ & $\begin{array}{l}\text { Low PCS } \\
\mathrm{M}(\mathrm{SD})\end{array}$ & $\begin{array}{l}\text { High PCS } \\
M(S D)\end{array}$ & $\begin{array}{l}\text { Low PCS } \\
\mathrm{M}(\mathrm{SD})\end{array}$ & $\begin{array}{l}\text { High PCS } \\
\mathrm{M}(\mathrm{SD})\end{array}$ & $\begin{array}{l}\text { Low PCS } \\
\mathrm{M}(\mathrm{SD})\end{array}$ & $\begin{array}{l}\text { High PCS } \\
M(S D)\end{array}$ \\
\hline Performance duration (min) & $1.92(0.86)$ & $3.32(2.67)$ & $7.02(5.14)$ & $4.05(2.04)$ & $2.95(1.83)$ & $3.87(3.48)$ & $2.29(1.39)$ & $3.15(1.69)$ \\
\hline Number of button presses per second & $3.94(0.72)$ & $3.59(0.97)$ & $3.41(1.44)$ & $3.42(0.94)$ & $3.86(0.92)$ & $4.14(0.56)$ & $3.75(1.30)$ & $3.42(1.25)$ \\
\hline Proportion of hits & $0.58(0.12)$ & $0.58(0.17)$ & $0.50(0.22)$ & $0.52(0.14)$ & $0.58(0.15)$ & $0.63(0.09)$ & $0.56(0.20)$ & $0.51(0.19)$ \\
\hline Proportion of false positives & $0.25(0.05)$ & $0.20(0.06)$ & $0.24(0.10)$ & $0.22(0.07)$ & $0.26(0.06)$ & $0.26(0.05)$ & $0.25(0.09)$ & $0.22(0.08)$ \\
\hline
\end{tabular}

$\mathrm{M}=$ mean; PTP = perceived threat of pain questionnaire; $\mathrm{SD}=$ standard deviation. 
High threat context

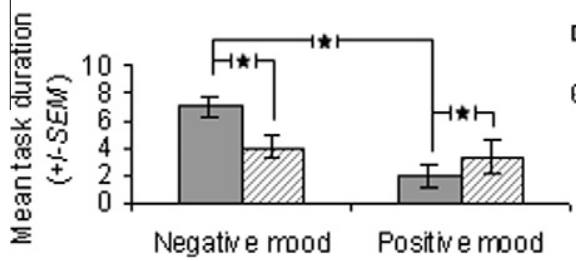

Low threat context
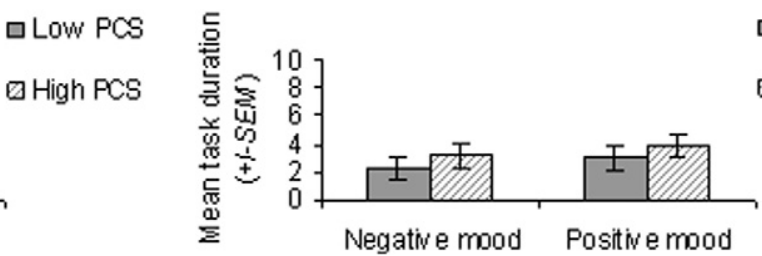

口Low PCS

ø High PCS

Fig. 3. The relationship between pain catastrophizing and performance duration (minutes) dependent on mood and threat condition.

higher pain catastrophizing was associated with less duration during a painful finger pressing task when participants experienced negative moods. In contrast, when participants experienced positive moods, higher pain catastrophizing was associated with greater performance duration. This corroborates research demonstrating that mood may have opposing effects on behavior depending on goal pursuit $[8-10,27,29,30,39,40,44,45,60]$, and supports affective-motivational models, such as the mood-as-input and mood-as-information models [31,42]. These models put forward that current mood is informational on the presence of threat or safety during the performance of a task. The present findings indicate that, relative to low pain catastrophizers, individuals with high pain catastrophizing tend to infer danger from their negative mood and relative safety from their positive mood, which in turn leads to respectively less or greater performance duration during painful activities. Moreover, as predicted, the present study demonstrates that the relationship between pain catastrophizing and performance duration and the modulating effect of mood was most pronounced when the pain stimulus was highly threatening. This finding is in line with theories emphasizing that stable cognitive schemas about threat influence behavior when activated by threat-relevant contextual cues $[4,13,17,28]$.

An unpredicted finding was that mood and threat context did not influence performance duration within the relatively high catastrophizing group in the present study. High catastrophizing participants did not show less performance duration in a negative than a positive mood, particularly in a high threatening context. A possible explanation is that individuals with high pain catastrophizing developed stable cognitive schemas about pain and less flexibly adapt to changing contexts [35], diminishing their sensitivity to situational factors, such as mood and threat manipulations. In line with this suggestion, the present study demonstrated that high catastrophizing individuals overall experienced higher negative moods, threat, and pain unpleasantness than low catastrophizing individuals, irrespective of mood and threat context. Nonetheless, both the mood and the threat manipulations were equally successful in both the low and the high catastrophizing groups. Moreover, pain catastrophizing was measured in a pain-free sample with lower levels of catastrophizing as compared to patients with chronic pain. For example, a mean PCS score of $M=12.52$ ( $S D=6.62$, range 0 to 32) was obtained in the present study, which was similar to other pain-free samples [43]. However, a mean PCS score of M $(\mathrm{SD})=25.5$ (11.3) to 33.9 (11.9) was obtained in patients with chronic musculoskeletal pain [47]. Therefore, an alternative explanation is that not stable cognitive schemas but the absence of individuals with heightened levels of pain catastrophizing resulted in the nonsignificant mood and threat effects in the high catastrophizing group. Future research is required replicating the present study in patients with chronic pain because these patients may have relatively high levels of pain catastrophizing. Note that the present paradigm may be particularly relevant for patients with computer-related upper extremity pain because the Martians task evokes painful sensations due to prolonged computer use.

Although no specific hypotheses were formulated with respect to the low pain catastrophizing group, an intriguing finding was that mood and threat context influenced performance duration particularly in relatively low catastrophizing individuals. Individuals with low levels of pain catastrophizing in a high threat context showed greater performance duration when in a negative than a positive mood. No such mood effect was demonstrated in a low threat context. Although to the best of our knowledge this is the first study demonstrating a mood effect in low catastrophizing people, there is one study that showed similar findings. Researchers [53] found that patients with low back pain demonstrated greater performance duration on a physical exercise task in a negative than in a positive mood. Moreover, they found that this effect was most pronounced in patients with low negative affect. Given that negative affectivity is highly correlated with pain catastrophizing [24,36] these results [53] may be in line with the present findings. The mood-as-input model may cautiously provide an explanation for these findings [59]. Research has demonstrated that participants with low pain catastrophizing are more inclined to adopt achievement goals [22]. Therefore, a negative as opposed to a positive mood may have informed the low catastrophizing participants in the present study that they had not performed well enough on the task, leading to greater performance duration. However, the reason that low and high catastrophizing individuals adopted respectively achievement or pain-avoidance goals particularly in a high threatening context remains unknown. An explanation may be that low and high catastrophizing individuals process threatening information differently, influencing their goal activation. Research on anxiety disorders has suggested that low-anxiety individuals tend to avoid consciously perceived threatening information, whereas high-anxiety individuals tend to focus on threatening information and show difficulty disengaging from it [13]. It is possible that in the present study, the low catastrophizing individuals drew their attention away from pain-avoidance goals elicited by the threat instruction, and in turn focused on the opposing achievement goals (i.e., save the planet from a Martian invasion), whereas the high catastrophizing individuals focused on painavoidance goals in response to the threat instruction (i.e., avoid harm to the arm muscle). As a result, mood may have informed low catastrophizing individuals about their performance and high pain catastrophizing individuals about the possible threat of the task. Note that no achievement goals were measured in the present study. Therefore, we can only speculate about the possible mechanisms explaining performance duration in the low pain catastrophizing individuals. Future research is required in which activation of achievement goals is measured in low catastrophizing individuals in a threatening context.

The results of the present study demonstrated that the Martians task was a painful task. However, the task was particularly painful for individuals with high pain catastrophizing. This finding corroborates studies demonstrating that individuals with high levels of catastrophizing selectively attend to painful sensations and interpret ambiguous sensations as painful [50,51,54].

Task persistence could not be explained by physical load because pain catastrophizing, threat and mood context were unrelated to the number of button presses per second during the Martians task. However, participants with a positive mood showed 
a greater proportion of hits, i.e., correct button presses in response to the appearance of a Martian, than participants with negative moods. Indeed, positive moods can engender more quick and efficient information processing [19] than negative moods [18,41]. This suggests that a positive mood elicited faster information processing and responding to Martian pictures in the present study, leading to a greater number of hits when participants experienced positive than negative moods.

Some caution is warranted about the generalization of the present findings to patients with chronic pain because the sample consisted of only pain-free students. It is possible that in the academic context students are inclined to adopt achievement goals, which in turn may have influenced their performance duration. In turn, patients with chronic pain may respond differentially to threat and mood manipulations because of their acquired cognitive pain schemes. Note, however, that the inclusion of pain-free individuals may provide insight into the mechanisms that contribute to the onset of chronic pain complaints.

In sum, the present study indicates that the relationship between pain catastrophizing and task persistence during painful activities is influenced by situational factors such as mood and threat context. In line with modern affective motivational models of pain, these findings provide support for the assumption that stable cognitive schemas about pain and threat are activated by threat contexts and that mood may serve as an informational source about whether a task should be avoided or not.

\section{Acknowledgements}

This study was supported by a Vici Grant (No. 453-04-003) provided by the Netherlands Organisation for Scientific Research (NWO). The study was presented as a poster at the European Federation of IASP chapters (EFIC) Pain in Europe Conference, Hamburg, August 24-29, 2011. The authors report no conflicts of interest.

\section{Appendix A}

\section{A.1. High threat orienting passage}

Before we begin, carefully read the following information about the repetitive strain injury (RSI) task. You will be requested to perform 1 similar movement with your forefinger repeatedly. Repetitive movement with the same muscle in the arm, in this case the musculus extensor digitorum, can lead to RSI. RSI is caused by a swollen or inflamed tendon sheath, caused by longstanding rubbing of the tendon against bones and ligaments. RSI causes a constant pain in neck, arms, and hands, and can even continue at night. Warning signs include sensations of tingling, weakness or loss of grab ability, a numb feeling, and sometimes turning pale. A victim is often unaware of the development of RSI. However, RSI can permanently damage your body tissue. Severe cases can lead to the incapacity of loading the muscle, wearing a holding brace permanently, and the inability to perform daily activities. Keep this warning in mind during the RSI task.

\section{A.2. Low threat orienting passage}

Before we begin, carefully read the following information about the Martians task. You will be requested to perform 1 similar movement with your forefinger repeatedly. The Martians task is a safe and effective experimental procedure. A review of the literature showed that over 50 experiments have used the Martians task with various populations, including young children, pregnant women, elderly people, college students, and persons with chronic medical conditions. Therefore, it turns out that this task is a popular and safe method for scientific research. The Martians task is harmless. You may experience short-term discomfort or tiredness in the muscles in the arm during and shortly after the experiment. However, these sensations will disappear soon. The procedure is safe because the loading of the muscles is low and speed of movement is controlled. Keep this reassurance in mind during the Martians task.

\section{References}

[1] Arcediano F, Ortega N, Matute H. A behavioural preparation for the study of human Pavlovian conditioning. Q J Exp Psychol B 1996;49:270-83.

[2] Arnzt A, Rauner M, van den Hout M. "If I feel anxious, there must be danger": ex-consequentia reasoning in inferring danger in anxiety disorders. Behav Res Ther 1995;33:917-25.

[3] Boston A, Sharpe L. The role of threat-expectancy in acute pain: effects on attentional bias, coping strategy effectiveness and response to pain. Pain 2005;119:168-75.

[4] Bower GH. Mood and memory. Am Psychol 1981;36:129-48.

[5] Bradley MM, Lang PJ. Measuring emotion: the self-assessment manikin and the semantic differential. J Behav Ther Exp Psychiatry 1994;25:49-59.

[6] Bradley BP, Mogg K, Millar N. Biases in overt and covert orienting to emotional facial expressions. Cogn Emot 2000;14:798-808.

[7] Crombez G, Vlaeyen JWS, Heuts PHTG, Lysens R. Pain-related fear is more disabling than pain itself: evidence on the role of pain-related fear in chronic low back pain disability. Pain 1999;80:329-39.

[8] Davey GCL, Eldridge F, Drost J, MacDonald BA. What ends a worry bout? An analysis of changes in mood and stop rule use across the catastrophizing interview task. Behav Res Ther 2007;45:1231-43.

[9] Davey GCL, Startup HM, MacDonald CB, Jenkins D, Patterson K. The use of "as many as can" vs "feel like continuing" stop rules during worrying. Cogn Ther Res 2005;29:155-69.

[10] Davey GCL, Startup HM, Zara A, MacDonald CB, Field AP. The perseveration of checking thoughts and mood-as-input hypothesis. J Behav Ther Exp Psychiatry 2003:34:141-60.

[11] DeCoster J, Iselin AM, Gallucci M. A conceptual and empirical examination of justifications for dichotomization. Psychol Methods 2009;14:349-66.

[12] Eccleston C, Williams ACDC, Morley S. Psychological therapies for the management of chronic pain (excluding headache) in adults. Cochrane Database Syst Rev 2009;2:CD007407.

[13] Edwards MS, Burt JS, Lipp OV. Selective attention for masked and unmasked emotionally toned stimuli: effects of trait anxiety, state anxiety, and test order. Br J Psychol 2010;101:325-43.

[14] Edwards RR, Fillingim RB. Ethnic differences in thermal pain responses. Psychosom Med 1999;61:346-54

[15] Gangemi A, Mancini F, van den Hout M. Feeling guilty as a source of information about threat and performance. Behav Res Ther 2007;45:2387-96.

[16] George SZ, Dannecker EA, Robinson ME. Fear of pain, not pain catastrophizing predicts acute pain intensity, but neither factor predicts tolerance or blood pressure reactivity: an experimental investigation in pain-free individuals. Eur J Pain 2006;10:457-65.

[17] Gray JA, McNaughton N. The neuropsychology of anxiety. Oxford: New York; 2000.

[18] Hirt ER, McDonald HE, Melton RJ. Processing goals and the affect-performance link: mood as main effect or mood as input? In: Martin LL, Tesser A, editors. Striving and feeling: interactions among goals, affect and selfregulation. Mahwah, NJ: Erlbaum; 1996. p. 303-28.

[19] Isen AM. An influence of positive affect on decision making in complex situations: theoretical issues with practical implications. J Consum Psychol 2001;11:75-85.

[20] Jackson T, Pope L, Nagasaka T, Fritch A, Lezzy T, Chen H. The impact of threatening information about pain on coping and pain tolerance. Br Health J Psychol 2005;10:441-51.

[21] Janssen R. EMIUM: Effect Monitoring via Internet Universiteit Maastricht Version 1.3. Maastricht: Research Institute of Experimental Psychopathology, Maastricht University, 2008.

[22] Karsdorp PA, Vlaeyen JWS. Goals matter: both achievement and painavoidance goals are associated with pain severity and disability in patients with low back and upper extremity pain. Pain 2011;152:1382-90.

[23] Lang PJ. Behavioral treatment and bio-behavioral assessment: compute applications. In: Sidowski JB, Johnson JH, Williams TA, editors. Technology in mental health care delivery systems. Norwood, NJ: Ablex; 1980.

[24] Lee JE, Watson D, Law LAF. Lower-order pain-related constructs are more predictive of cold pressor pain ratings than higher-order personality traits. J Pain 2010;11:681-91.

[25] MacCallum RC, Zhang S, Preacher KJ, Rucker DD. On the practice of dichotomization of quantitative variables. Psychol Methods 2002;7:19-40.

[26] MacDonald B, Davey GCL. A mood-as-input account of perseverative checking: the relationship between stop rules, mood and confidence in having checked successfully. Behav Res Ther 2005;43:69-91.

[27] MacDonald B, Davey GCL. Inflated responsibility and perseverative checking: the effect of negative mood. J Abnorm Psychol 2005;114:176-82.

[28] MacLeod C, Rutherford EM. Anxiety and the selective processing of emotiona information: mediating roles of awareness, trait and state variables, and personal relevance of stimulus materials. Behav Res Ther 1992;30: 479-91. 
[29] Mathews A, MacLeod C. Cognitive approaches to emotion and emotional disorders. Ann Rev Psychol 1994;45:25-50.

[30] Martin LL, Abend T, Sedikides C, Green JD. How would I feel if ...? Mood as input to a role fulfillment evaluation process. J Pers Soc Psychol 1997;73:242-53.

[31] Martin LL, Ward W, Achee JW, Wyer RS. Mood as input: people have to interpret the motivational implications of their moods. J Pers Soc Psychol 1993;64:317-26.

[32] McGowan N, Sharpe L, Refshauge K, Nicholas MK. The effects of attentional retraining and threat expectancy in response to acute pain. Pain 2009;142:101-7.

[33] Meredith PJ, Strong J, Feeney JA. The relationship of adult attachment to emotion, catastrophizing, control, threshold and tolerance, in experimentallyinduced pain. Pain 2006;120:44-52.

[34] Meulders A, Vervliet B, Vansteenwegen D, Hermans D, Baeyens F. A new tool for assessing context conditioning induced by US-unpredictability in humans: the Martians task restyled. Learn Motiv 2010;42:1-12.

[35] Moriarty O, McGuire BE, Finn DP. The effect of pain on cognitive function: a review of clinical and preclinical research. Prog Neurobiol 2011:93:385-404.

[36] Mounce C, Keogh E, Eccleston C. A principal components analysis of negative affect-related constructs relevant to pain: evidence for a three component structure. J Pain 2010;11:710-7.

[37] Price DD, Bush FM, Long S, Harkins SW. A comparison of pain measurement characteristics of mechanical visual analogue and simple numerical rating scales. Pain 1994;56:217-26.

[38] Rhudy JL, France CR, Bartley EJ, Williams AE, McCabe KM, Russell JL. Does pain catastrophizing moderate the relationship between spinal nociceptive processes and pain sensitivity? J Pain 2009;10:860-9.

[39] Sanna LJ, Meier S, Wegner EA. Counterfactuals and motivation: mood as input to affective enjoyment and preparation. Br J Soc Psychol 2001;40:235-56.

[40] Sanna LJ, Parks CD, Chang EC. Mixed-motive conflict in social dilemmas: mood as input to competitive and cooperative goals. Group Dyn 2003;7:26-40.

[41] Schwarz N, Bless H. Happy and mindless, but sad and smart.The impact of affective states on analytic reasoning. In: Forgas JP, editor. Emotion and social judgment. Oxford, England: Pergamon; 1991. p. 55-71.

[42] Schwarz N, Clore GL. Mood as information: 20 years later. Psychol Inq 2003;14:196-303.

[43] Severeijns R, van den Hout MA, Vlaeyen JWS. The causal status of pain catastrophizing: an experimental test with healthy participants. Eur J Pain 2005;9:257-65.

[44] Startup HM, Davey GCL. Inflated responsibility and the use of stop rules for catastrophic worrying. Behav Res Ther 2003;41:495-503.

[45] Startup HM, Davey GCL. Mood as input and catastrophic worrying. J Abnorm Psychol 2001;110:83-96.
[46] Sullivan MLJ, Bishop SR, Pivik J. The pain catastrophizing scale: development and validation. Psychol Assess 1995;7:524-32.

[47] Thibault P, Loisel P, Durand M, Catchlove R, Sullivan MJL. Psychological predictors of pain expression and activity intolerance in chronic pain patients. Pain 2008;139:47-54.

[48] Van Damme S, Crombez G, Vlaeyen JWS, Goubert L, Van den Broeck A, Van Houdenhove B. De pain catastrophizing scale: psychometrische karakteristieken en normering. Gedragsther 2000;33:209-20.

[49] Van Damme S, Crombez G, Bijttebier P, Goubert L, Van Houdenhove BA Confirmatory factor analysis of the pain catastrophizing scale: invariant factor structure across clinical and non-clinical populations. Pain 2002;96:319-24.

[50] Van Damme S, Crombez G, Eccleston C. Retarded disengagement from pain cues: the effects of pain catastrophizing and pain expectancy. Pain 2002;100:111-8

[51] Van Damme S, Crombez G, Eccleston C. Disengagement from pain: the role of catastrophic thinking about pain. Pain 2004;107:70-6.

[52] Van Damme S, Crombez G, van Nieuwenborgh-De Wever K, Goubert L. Is distraction less effective when pain is threatening? An experimental investigation with the cold pressor task. Eur J Pain 2008;12:60-7.

[53] Van den Hout JHC, Vlaeyen JWS, Houben RMA, Soeters APM, Peters ML. The effect of failure feedback and pain-related fear on pain report, pain tolerance, and pain avoidance in chronic low back pain patients. Pain 2001:92:247-57.

[54] Vancleef LM, Peters ML, De Jong PJ. Interpreting ambiguous health and bodily threat: are individual differences in pain-related vulnerability constructs associated with a non-line negative interpretation bias? J Behave Ther Exp Psychiatry 2009;40:59-69.

[55] Vancleef LM, Peters ML, Roelofs J, Asmundson GJ. Do fundamental fears differentially contribute to pain-related fear and pain catastrophizing? An evaluation of the sensitivity index. Eur J Pain 2006;10:527-36.

[56] Vlaeyen JWS, Hanssen M, Goubert L, Vervoort T, Peters M, van Breukelen G, Sullivan MJL, Morley S. Threat of pain influences social context effects on verbal report and facial expression. Behav Res Ther 2009;47:774-82.

[57] Vlaeyen JWS, Kole-Snijders AMJ, Boeren RGB, van Eek H. Fear of movement/ (re) injury in chronic low back pain and its relation to behavioral performance. Pain 1995;62:363-72.

[58] Vlaeyen JWS, Linton SJ. Fear-avoidance and its consequences in chronic musculoskeletal pain: a state of the art. Pain 2000;85:317-32.

[59] Vlaeyen JWS, Morley S. Active despite pain: the putative role of stop-rules and current mood. Pain 2004;110:512-6.

[60] Watkins E, Mason A. Mood as input and rumination. Pers Indiv Differ 2002;32:577-87.

[61] Wells A, Papageorgiou C. Social phobic interoception: effects of bodily information on anxiety, beliefs and self-processing. Behav Res Ther 2001;39:1-11. 